\title{
An Innovative Halogen-Free Flame-Retardant Thermosetting Carbon Fiber Laminate
}

\author{
Chun-Mu Wu, Lin-Lin Huang, ${ }^{1}$ and Shin-Ku Lee ${ }^{2 *}$ \\ Department of Mechanical Engineering and Automation Engineering, Kao Yuan University, \\ Kaohsiung 821, Taiwan, R.O.C. \\ ${ }^{1}$ Department of Architecture and Interior Design, Cheng Shiu University, Kaohsiung 833, Taiwan, R.O.C. \\ ${ }^{2}$ Research Center for Energy Technology and Strategy, National Cheng-Kung University, Tainan 701, Taiwan, R.O.C.
}

(Received August 31, 2015; accepted February 12, 2016)

Keywords: flame-retardant, carbon fiber laminate, DOPO-DICY

In this study, we evaluated a flame-retardant hardener for epoxy resins and a flame-retardant resin consisting of the same components, which can be applied to materials used in the aerospace, automotive, and construction industries. To overcome the predicaments associated with curing agents such as 9,10-dihydro-9-oxa-10-phosphaphenanathrene-10-oxide (DOPO)-dicyandiamide (DICY) that are difficult to synthesize successfully, we provided novel flame-retardant hardeners by attaching the phosphorous-containing group of DOPO to a carbon of DICY. We also provide a method beneficial for mass production of the flame-retardant hardener for epoxy resins. To measure the characteristics of the flame-retardant hardener, carbon fabrics were preimpregnated with these epoxy resins to form a halogen-free flame-retardant thermosetting carbon fiber prepreg. Then, samples of carbon fiber laminate with eight layers of prepregs were pressed at $180{ }^{\circ} \mathrm{C}$ under thermosetting conditions. The tensile, compressive, flexural, interlaminar shear, and in-plane shear properties of the carbon fiber laminate were measured in accordance with American Society for Testing and Materials (ASTM) D3039, D3410, D790, D2344, and D4255 standard testing protocols, respectively. The results indicate that the proposed material provides high strength and stiffness. Finally, according to the flammability rating of the UL-94 standard method, all samples were determined to be V-0. The results demonstrate that a flame-retardant hardener for epoxy resins could be mixed with resins to produce a standard qualified flame-retardant resin based on the UL-94 standards.

\section{Introduction}

When resins are used as a carbon fiber prepreg material, the monomer of the resins is used to make products with flame-retardant characteristics. Although the carbon fiber prepreg material made with brominated resins usually has good flame-retardant characteristics, the brominated resins produce highly corrosive bromine free radicals, hydrogen bromide ( $\mathrm{HBr}$ ), high toxic polybrominedibenzofurans, and polybrominedibenzodioxins when incinerated. These substances cause huge damage to both people and the environment. To overcome these problems, a phosphorus-containing group in 9,10-dihydro-9-oxa-10-phosphaphenanathrene-10-oxide (DOPO) is attached to the epoxy resin to provide a flame-retardant resin, which can replace the toxic ${ }^{\bar{*}}$ Corresponding author: e-mail: sklee1015@gmail.com 
brominated resin. When a product made of DOPO is heated at a high temperature, the phosphoruscontaining group in DOPO produces nonvolatile phosphorous compounds such as phosphoric acid $\left(\mathrm{H}_{3} \mathrm{PO}_{4}\right)$ and polyphosphorous acid. Because polyphosphorous acid has the ability to protonate organic molecules and has a strong dehydrating effect, and because $\mathrm{H}_{3} \mathrm{PO}_{4}$ can be an agglutinant for carbon to form an insulated layer and also a strong dehydrating effect, nonvolatile phosphorous compounds can import a desirable flame-retardant characteristics to resins.

Generally, resins for carbon fiber prepreg materials must be synthesized with a curing agent (hardener) and treated with other processes. Because DOPO can provide flame-retardant characteristics to resins, a halogen-free flame-retardant carbon fiber prepreg material can also be obtained using a DOPO-containing curing agent.

This hypothesis, that a curing agent attached to a phosphorous-containing group in DOPO may give rise to a flame-retardant material, has been well known in related areas. However, a feasible and specific process and technique have still not been developed. Many articles ${ }^{(1,2)}$ have disclosed a compound of the sort represented in Fig. 1.

This compound is obtained by attaching a phosphorous-containing group of DOPO to a curing agent (dicyandiamide, DICY) and is called DOPO-DICY. According to the preparation method disclosed in the publications, DICY must be heated at $120{ }^{\circ} \mathrm{C}$ until it is completely melted. However, DICY has a high melting point of about $209.5^{\circ} \mathrm{C}$. It is difficult to use the conventional apparatus as disclosed in the published literature to synthesize DOPO-DICY. Moreover, there is still a need to develop other curing agents to improve technical progress.

To overcome the problem that curing agents such as DOPO-DICY (an agent for curing materials) are difficult to synthesize successfully, a novel flame-retardant hardener made by attaching the phosphorous-containing group of DOPO to a carbon of DICY is proposed in this study. We also provide a method beneficial for mass production of the flame-retardant hardener for epoxy resins.

\section{Preparation and Manufacture of Halogen-Free Flame-Retardant Thermosetting Carbon Fiber Laminate}

The preparation of a flame-retardant hardener for epoxy resin is as follows.

(1) A reaction flask equipped with an electric stirrer, a thermocouple, and an adjustable thermostat heater was provided. The reaction flask should be filled with nitrogen to isolate the contents from the air and moisture.

(2) An appropriate amount of DOPO was added to the reaction flask and heated to a temperature ranging from 120 to $135^{\circ} \mathrm{C}$ until the DOPO was completely melted.

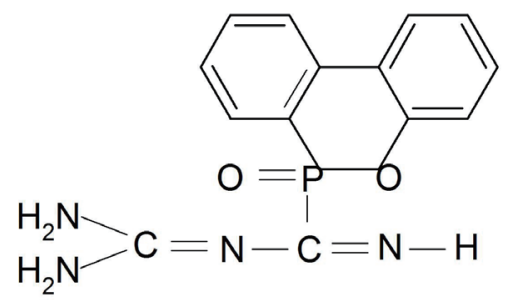

Fig. 1. Typical structure of DOPO-DICY.(1,2) 
(3) An appropriate amount of DOPO was added to the reaction flask to form a mixture. In this step, the reaction temperature must be higher than $110{ }^{\circ} \mathrm{C}$ to ensure that the DOPO was in a molten state. In the sample prepared, the molar ratio of DOPO to DICY was 1:1, 1.8:1, and 5:1.

(4) The reaction flask was slowly heated to $175^{\circ} \mathrm{C}$ from 4 to $14 \mathrm{~h}$. In the samples prepared, the reactions were carried out for 6 and $14 \mathrm{~h}$ when the molar ratio of DOPO to DICY was 1:1. The reactions were carried out for 2 and $8 \mathrm{~h}$ when the molar ratio of DOPO to DICY was 1.8:1. The reaction was carried out for $14 \mathrm{~h}$ when the molar ratio of DOPO to DICY was 5:1.

(5) The mixtures obtained in the precious step were subsequently cooled. The mixtures comprising three products represented by structures (A), (B), and (C) were produced, as shown in Fig. 2.

After the flame-retardant hardener for epoxy resins were manufactured, high grade carbon fabrics were pre-impregnated with the resins to form a halogen-free flame-retardant thermosetting carbon fiber prepreg. Then, samples of the halogen-free flame-retardant thermosetting carbon fiber laminate (Fig. 3) with eight layers of prepregs were pressed at $180{ }^{\circ} \mathrm{C}$ under thermosetting conditions. The thickness of this laminate was $1.38 \mathrm{~mm}$.

\section{Performance Testing of Halogen-Free Flame-Retardant Thermosetting Carbon Fiber Laminate}

The tensile, compressive, flexural, interlaminar shear, and in-plane shear properties of the halogen-free flame-retardant thermosetting carbon fiber laminate were measured by American Society for Testing and Materials (ASTM) D3039, D3410, D790, D2344, and D4255 standard

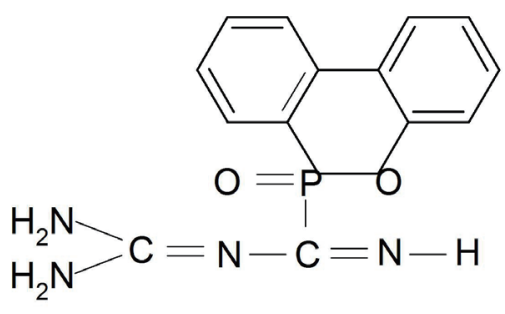

(a)

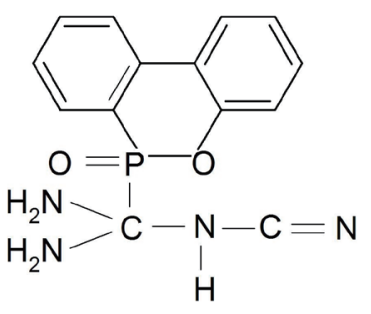

(b)

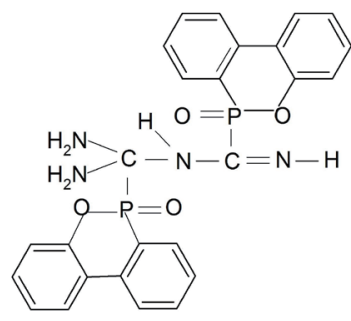

(c)

Fig. 2. Structures of DOPO-DICY samples synthesized in this study.

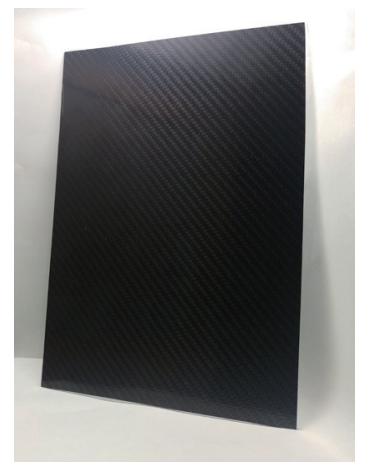

Fig. 3. Picture of halogen-free flame-retardant thermosetting carbon fiber laminate. 
testing protocols, ${ }^{(3-7)}$ respectively. All data were generated in the 0 direction and tested at room temperature. The measured mechanical properties of the halogen-free flame-retardant thermosetting carbon fiber laminate are shown in Tables 1-5. The proposed carbon fiber laminates have the following averaged properties: tensile strength, $1109.67 \mathrm{MPa}$; tensile modulus, $128.97 \mathrm{GPa}$; compressive strength, 1003.33 MPa; compressive modulus, 134.95 GPa; flexural strength, 2306.33 $\mathrm{MPa}$; flexural modulus, $131.94 \mathrm{GPa}$; interlaminar shear strength, $12483.99 \mathrm{MPa}$; interlaminar shear modulus, $36.32 \mathrm{GPa}$; in-plane shear strength, $43.24 \mathrm{MPa}$; in-plane shear modulus, $6.048 \mathrm{GPa}$. These results indicate that our proposed halogen-free flame-retardant thermosetting carbon fiber laminate provided high strength and stiffness. The mechanical properties of the composites can be enhanced by changing the fiber orientation and increasing the number of laminates. ${ }^{\left({ }^{8}\right)}$

In addition, the flame-retardant properties of the halogen-free flame-retardant thermosetting carbon fiber laminate were determined by official standard flame-retardant UL-94 test. ${ }^{(9)}$ The results for samples 1 to 5 are listed in Table 6 . According to the flammability rating of the UL-94 standard method, the qualified ratings are classified as V-0, V-1, and V-2. As shown in Table 6, all samples are self-extinguishing, which meets the UL-94 V-0 classification. The results demonstrate that the flame-retardant hardener for the epoxy resins could be mixed with resins to produce a standard qualified flame-retardant resin based on the UL-94 standards. Hence, the flame-retardant resin material could be used to replace the halogenated resin in conventional processes.

Table 1

Tensile properties of samples by ASTM D3039.

\begin{tabular}{lcccccc}
\hline No. & $\begin{array}{l}\text { Width } \\
(\mathrm{mm})\end{array}$ & $\begin{array}{c}\text { Thickness } \\
(\mathrm{mm})\end{array}$ & $\begin{array}{c}\text { Tensile load } \\
(\mathrm{kN})\end{array}$ & $\begin{array}{c}\text { Tensile strength } \\
(\mathrm{MPa})\end{array}$ & $\begin{array}{c}\text { Tensile modulus } \\
(\mathrm{GPa})\end{array}$ & Failure code \\
\hline 1 & 10.50 & 1.36 & 12.238 & 857.036 & 129.19 & SGM \\
2 & 10.49 & 1.34 & 17.241 & 1226.537 & 131.87 & SGM \\
3 & 10.45 & 1.40 & 17.800 & 1216.683 & 125.09 & SGM \\
4 & 10.45 & 1.40 & 16.899 & 1155.077 & 130.18 & SGM \\
5 & 10.47 & 1.37 & 156.781 & 1093.016 & 128.51 & SGM \\
\hline
\end{tabular}

Table 2

Compressive properties of samples by ASTM D3410.

\begin{tabular}{lcccccc}
\hline No. & $\begin{array}{l}\text { Width } \\
(\mathrm{mm})\end{array}$ & $\begin{array}{c}\text { Thickness } \\
(\mathrm{mm})\end{array}$ & $\begin{array}{c}\text { Compressive } \\
\text { load }(\mathrm{kN})\end{array}$ & $\begin{array}{c}\text { Compressive } \\
\text { strength }(\mathrm{MPa})\end{array}$ & $\begin{array}{c}\text { Compressive } \\
\text { modulus }(\mathrm{GPa})\end{array}$ & Failure code \\
\hline 1 & 24.01 & 1.37 & 26.312 & 799.91 & 109.91 & TAT \\
2 & 24.03 & 1.40 & 36.211 & 1076.37 & 129.99 & TAT \\
3 & 24.02 & 1.32 & 36.414 & 1148.47 & 155.90 & TAT \\
4 & 24.01 & 1.34 & 36.402 & 1131.43 & 138.41 & TAT \\
5 & 24.02 & 1.37 & 28.315 & 860.44 & 140.55 & TAT \\
\hline
\end{tabular}

Table 3

Flexural properties of samples by ASTM D790.

\begin{tabular}{lcccccc}
\hline No. & $\begin{array}{c}\text { Length } \\
(\mathrm{mm})\end{array}$ & $\begin{array}{c}\text { Width } \\
(\mathrm{mm})\end{array}$ & $\begin{array}{c}\text { Thickness } \\
(\mathrm{mm})\end{array}$ & $\begin{array}{c}\text { Flexural load } \\
(\mathrm{kN})\end{array}$ & $\begin{array}{c}\text { Flexural strength } \\
(\mathrm{MPa})\end{array}$ & Modulus $(\mathrm{GPa})$ \\
\hline 1 & 50.52 & 12.93 & 1.38 & 1.397 & 2162.03 & 117.00 \\
2 & 50.48 & 12.81 & 1.32 & 1.244 & 2123.45 & 136.22 \\
3 & 50.52 & 12.95 & 1.35 & 1.522 & 2456.95 & 139.08 \\
4 & 50.58 & 12.98 & 1.36 & 1.448 & 2297.92 & 136.18 \\
5 & 50.52 & 12.92 & 1.36 & 1.533 & 2491.32 & 131.36 \\
\hline
\end{tabular}


Table 4

Interlaminar shear properties of samples by ASTM D2344.

\begin{tabular}{lccccc}
\hline No. & $\begin{array}{c}\text { Width } \\
(\mathrm{mm})\end{array}$ & $\begin{array}{c}\text { Thickness } \\
(\mathrm{mm})\end{array}$ & $\begin{array}{c}\text { Interlaminar load } \\
(\mathrm{kN})\end{array}$ & $\begin{array}{c}\text { Interlaminar } \\
\text { strength }(\mathrm{MPa})\end{array}$ & $\begin{array}{c}\text { Interlaminar } \\
\text { modulus }(\mathrm{GPa})\end{array}$ \\
\hline 1 & 9.88 & 1.35 & 7.195 & 12946.73 & 36.33 \\
2 & 9.65 & 1.35 & 7.029 & 12949.70 & 36.62 \\
3 & 9.84 & 1.32 & 6.237 & 11491.00 & 35.67 \\
4 & 9.84 & 1.32 & 7.051 & 12989.32 & 36.95 \\
5 & 9.88 & 1.33 & 6.985 & 12043.18 & 36.01 \\
\hline
\end{tabular}

Table 5

In-plane shear properties of samples by ASTM D4255.

\begin{tabular}{lccc}
\hline No. & $\begin{array}{c}\text { Ultimate load } \\
(\mathrm{kN})\end{array}$ & $\begin{array}{c}\text { Ultimate shear } \\
\text { strength }(\mathrm{MPa})\end{array}$ & Modulus $(\mathrm{GPa})$ \\
\hline 1 & 9.090 & 43.35 & 6.155 \\
2 & 8.915 & 43.21 & 6.015 \\
3 & 8.755 & 41.98 & 5.984 \\
4 & 9.114 & 43.65 & 6.213 \\
5 & 9.200 & 44.01 & 5.871 \\
\hline
\end{tabular}

Table 6

Flame-retardant properties of samples by UL-94.

\begin{tabular}{lccccc}
\hline No. & $\begin{array}{c}\text { Afterflame time } \\
t_{1}(\mathrm{~s})\end{array}$ & $\begin{array}{c}\text { Afterflame time } \\
t_{2}(\mathrm{~s})\end{array}$ & $\begin{array}{c}\text { Afterglow time } \\
t_{3}(\mathrm{~s})\end{array}$ & $\begin{array}{c}\text { Whether ignited } \\
\text { the cotton (Yes/No) }\end{array}$ & $\begin{array}{c}\text { Whether burn up to } \\
\text { the holding clamp (Yes/No) }\end{array}$ \\
\hline 1 & 3.5 & 0 & 0 & No & No \\
2 & 2.7 & 0 & 0 & No & No \\
3 & 4.0 & 0 & 0 & No & No \\
4 & 0 & 0 & 0 & No & No \\
5 & 0 & 0 & 0 & No & No \\
\hline
\end{tabular}

\section{Conclusions}

Carbon fibers with ultralight, energy-saving, and harder-than-steel properties have received significant attention from researchers. In particular, their applications in information technology, automobile, aviation, sports, and the military produce profits for manufactures. To overcome the problem that curing agents such as DOPO-DICY are difficult to synthesize successfully, a novel flame-retardant hardener formed by attaching the phosphorous-containing group of DOPD to the carbon of DICY is proposed in this study. This method for manufacturing a flame-retardant hardener for an epoxy resin can be directly applied in a resin curing process after a cooling step without additional purification. To evaluate the applicability of this hardener for manufacturing carbon fiber composite materials, high-grade carbon fabrics were preimpregnated with these epoxy resins to form a halogen-free flame-retardant thermosetting carbon fiber prepreg. Then, samples of the halogen-free flame-retardant thermosetting carbon fiber laminate with eight layers of prepregs were pressed at $180{ }^{\circ} \mathrm{C}$ under thermosetting conditions to measure the mechanical properties and flame-retardant characteristics of the proposed carbon fiber laminate. The obtained results indicate that the laminate has greater strength than steel and a V-0 flammability rating in accordance with the UL-94 standard. 
We conclude that the flame-retardant hardener for epoxy resins in accordance with this invention can replace conventional toxic halogenated resins and provide an environmental-friendly flameretardant hardener for epoxy resins for applications in the aerospace, automotive, marine, and construction industries.

\section{Acknowledgements}

The authors express their gratitude for financial support received for this study under project MOST 104-3113-E-006-019-CC2, without which this work would have been very difficult to do. We also thank Nan Pao Resins Chemical Group for their assistance on the sample preparation and testing.

\section{References}

1 M. Rakotomalala, S. Wagner, and M. Döring: Materials 3 (2010) 4300.

2 C. S. Wang, Z. Y. Xie, and Q. X. Lin: Taiwan Patent No. 593526 (2004)

3 American Society for Testing and Materials: ASTM D3039, Annual Book of ASTM Standards (2003).

4 American Society for Testing and Materials: ASTM D3410, Annual Book of ASTM Standards (2003).

5 American Society for Testing and Materials: ASTM D790, Annual Book of ASTM Standards (2010).

6 American Society for Testing and Materials: ASTM D2344, Annual Book of ASTM Standards (2006).

7 American Society for Testing and Materials: ASTM D4255, Annual Book of ASTM Standards (2007).

8 H. Rahmani, S. H. M. Najafi, and A. Ashori: J. Reinf. Plast. Compos. 33 (2014) 733.

9 Underwriters Laboratories: UL-94 (2009).

\section{About the Authors}

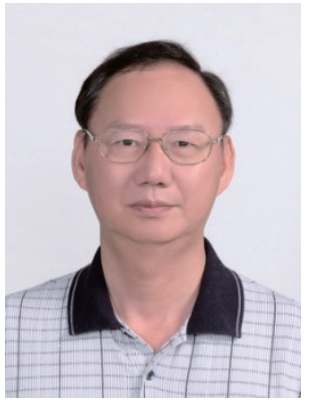

Chun-Mu Wu received his B.S. and M.S. degrees from Tamkang University, Taiwan, in 1981 and 1983, respectively, and his Ph.D. degree from National Cheng Kung University, Taiwan, in 1993. Since 1993, he has been an associate professor at Kao Yuan University. His research interests are in numerical analysis, heat transfer analysis, optimal control, and robotics.

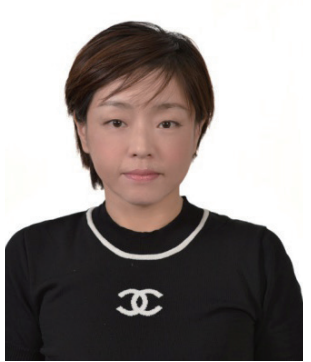

Lin-Lin Huang received her B.S. degree from Japan Women's University, Japan, in 1993 and her M.S. and Ph.D. degrees from National Cheng Kung University, Taiwan, in 2004 and 2011, respectively. Since 2011, she has been an assistant professor at Cheng Shiu University, Taiwan. Her research interests are in indoor air quality and health. 


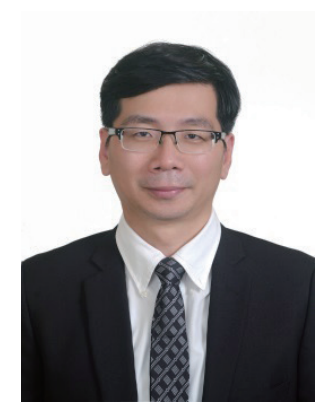

Shin-Ku Lee received his Ph.D. degree from National Sun Yat-Sen University, Taiwan, in 2001. From 2008 to 2014, he was an assistant research professor at National Cheng Kung University, Taiwan. Since 2015, he has been an associate research professor at National Cheng Kung University, Taiwan. His research interests are in green materials and building-integrated photovoltaics. 